\title{
Nasal Parameters of Ibibio and Yakurr Ethnic Groups of South South Nigeria
}

\author{
Chisom Favor Eliakim-Ikechukwu, ${ }^{1}$ Chinyere Michael Iro, ${ }^{2}$ Churchill Jonadab \\ Ihentuge, ${ }^{3}$ Theresa Effiong Bassey ${ }^{4}$ \\ ${ }^{124}$ Department of Anatomy, Faculty of Basic Medical Sciences, University of Calabar, Calabar, Nigeria. \\ ${ }^{3}$ Department of Anatomy, College of Medicine, Imo State University, Owerri, Imo State, Nigeria.
}

\begin{abstract}
The study involved 400 subjects, 200 each of the two ethnic groups(100 males and 100 females). The age range was 18-35years. Subjects with facial deformities or surgeries that involved the nasal region were excluded from the study. Subjects that have both parents and grandparents of each ethnic group and who have lived in that environment for at least the first 18years of their lifetime were selected for the study. The nasal length and width were measured using spreading calipers and nasal indices deducted from these measurements. Test for significance was done using the students' $t$-test. Results showed the nasal indices of the Ibibio males and females to be $86.58 \pm 1.20$ and $81.75 \pm 1.14$ respectively and for the Yakurr males and females, it was $77.76 \pm 0.82$ and 102.27 \pm 1.13 respectively. There was significant ethnic and gender differences in all the nasal parameters (nasal length, nasal width and nasal indices) at $p<0.05$. From the nasal indices the nose type of the Ibibio males is platyrrhine while that of the Ibibio females is mesorrhine, the Yakurr males also have mesorrhine nose type while the Yakurr females have platyrrhine nose type. With this result, nasal parameters could be a useful tool in gender and ethnic differentiation between the Ibibio and Yakurr ethnic groups.
\end{abstract}

Keywords: Mesorrhine, platyrrhine, nasal index, gender, ethnic group.

\section{Introduction}

The nose is one of the aesthetic units of the face [1]. There is a wide variation in the size and shape of the nose and ethnic influences can result in different appearance of the nose [2]. The variations in the form of the nose are greater than those found in the cranium and much greater than the body variation as a whole [3]. The nose has been attributed to natural selection in human evolution, the cold and dry climates having narrower noses while the warm and moist climates have broader noses [4]. Nasal elongation is influenced by adaptation to environment [5].

The human nose can be classified morphologically into roman or aquiline nose, the Greek or straight nose, the Nubian nose, the hawk nose, the snub nose and the celestial or turn up nose [6].

More elaborate morphological classification also exists. The human nose can also be classified using the nasal index. The nasal index is a ratio of the nasal width to the nasal length multiplied by 100 [4]. It is an ethnic sensitive anthropometrical index [7] and has become a useful tool in forensic science [8].

According to Williams et al., [9] The human nose can be grouped into three classes, the leptorrhine (long and narrow nose), the mesorrhine (medium) and the platyrrhine (broad nose) nose types using the nasal index. A nose type is said to be leptorrhine if the nasal index is 69.9 or les, mesorrhine if the nasal index is between 70-84.9 and platyrrhine if the nasal index is 85 and above. There is a very strong correlation between the nasal index and absolute humility [10] meaning that in a moist climate, the nasal index is high. Farkas et al., [11] has also documented that nasal index is related to regional and climatic differences. Nasal index of Africans is basically platyrrhine [12] and this has been associated with hot moisture [13]. Several works done in different ethnic groups of Nigeria have also documented predominantly platyrrhine nose type with a few mesorrhine nose type [14], [15], [16], [17], [18], [19].

Some workers also documented ethnic differences [14], [15], [16], [17] and gender differences [14], [15].

\section{Methodology}

Two ethnic groups, the Ibibio and the Yakurr ethnic groups of South South Nigeria were selected for this study. A total of four hundred subjects were involved in this work, two hundred for each ethnic group, one hundred males and one hundred females. This study was cited in two localities, the Ibibio land and the Yakurr land. The measurement procedure was verbally explained to the subjects and their consent got. Demographical data including the age, origin, duration of stay in the land of origin, parental and grandparental origin and history of facial surgeries and trauma wastaken. Subjects within the age range of 18-35years, of Ibibio and Yakurr ethnicity depending on the locality, having parents and grandparents from the same ethnic group and having no history or evidence of a facial surgery or trauma were selected for this study. 
The subjects were made to sits comfortably on a chair with the head held out straight in the anatomical position. The nasal length and nasal width were measured in centimeters using spreading calipers. The nasal length was measured as the straight distance from the nasion to the subnasale, while the nasal width was measured at the nasal base from ala to ala. Each measurement was taken twice and the average taken. The nasal index was then calculation by dividing the nasal width by the nasal length and multiplying by 100 [20]. The data obtained were subjected to statistical analysis using the students't-test. Test was significant at $\mathrm{p}<0.05$.

\section{Results}

3.1 Nasal parameters of the Ibibio and Yakurr ethnic groups

Table 1: Showing the mean nasal parameters of the Ibibio and Yakurr ethnic groups.

\begin{tabular}{|c|c|c|c|c|}
\hline \multicolumn{5}{|c|}{ ETHNIC GROUP } \\
\hline & \multicolumn{2}{|c|}{ IBIBIO } & \multicolumn{2}{|c|}{ YAKURR } \\
\hline NASAL PARAMETERS & MALE & FEMALE & MALE & FEMALE \\
\hline Nasal width & $4.14 \pm 0.4$ & $3.63 \pm 0.04$ & $4.00 \pm 0.04$ & \\
\hline $\begin{array}{l}3.82 \pm 0.04 \\
\text { (In centimeters) }\end{array}$ & & & & \\
\hline Nasal length & $4.81 \pm 0.04$ & $4.47 \pm 0.04$ & $5.16 \pm 0.04$ & \\
\hline $\begin{array}{l}3.77 \pm 0.05 \\
\text { (In centimeters) }\end{array}$ & & & & \\
\hline Nasal index & $86.58 \pm 1.20$ & $81.75 \pm 1.14$ & $77.76 \pm 0.82$ & \\
\hline $102.27 \pm 1.31$ & & & & \\
\hline
\end{tabular}

From table 1, nasal parameters of the males of the two ethnic groups under study are greater than that of the females except in the nasal index where the nasal index of the Yakurr females is greater than that of the males. From the nasal index, the Ibibio males have the platyrrhine nose type $(86.58 \pm 1.20)$ while the Ibibio females have the mesorrhine nose type. The Yakurr males and females have the mesorrhine (77.76 \pm 0.82$)$ and platyrrhine (102.27 \pm 1.13$)$ nose types respectively.

\subsection{Gender Variations}

Table 2: Comparing the mean nasal parameters of the male and female of the two ethnic groups

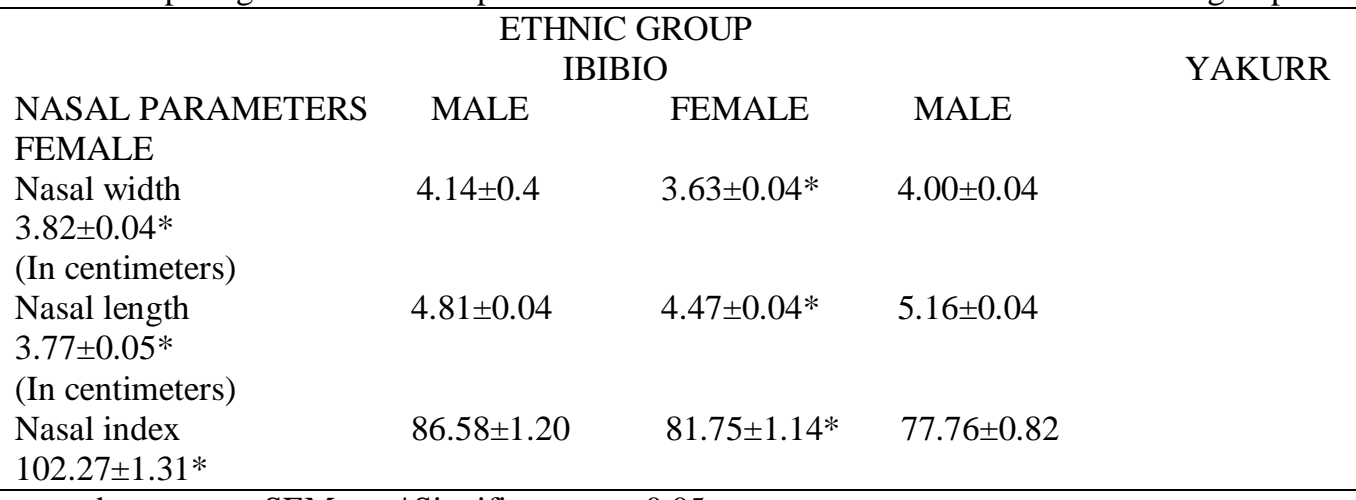

Data are expressed as mean \pm SEM $\quad *$ Significant at $\mathrm{p}<0.05$

Table 2 compares the means of the nasal parameters. There was significant differences $(\mathrm{p}<0.05)$ between the nasal width and the length of the Ibibio ethnic groups with males having higher values. The nasal index of the Ibibio males is higher than that of the Ibibio females and this difference is statistically significant at $\mathrm{p}<0.05$. The nasal width and the nasal length of the Yakurr males are higher than that of the females and these difference are statistically significant at $\mathrm{p}<0.05$.

The nasal index of the Yakurr female is significantly higher $(\mathrm{p}<0.05)$ than that of the Yakurr males. 


\subsection{Ethnic Variations}

Table 3: Comparing the mean nasal parameters between the Ibibio and Yakurr ethnic groups

\begin{tabular}{|c|c|c|c|c|}
\hline \multirow[b]{3}{*}{ NASAL PARAMETERS } & \multicolumn{4}{|c|}{ GENDER } \\
\hline & \multicolumn{2}{|c|}{ MALE } & \multicolumn{2}{|c|}{ FEMALE } \\
\hline & IBIBIO & YAKURR & IBIBIO & YAKURR \\
\hline $\begin{array}{l}\text { Nasal width } \\
\text { (In centimeter) }\end{array}$ & $4.14 \pm 0.04$ & $4.00 \pm 0.04 *$ & $3.63 \pm 0.04$ & $3.82 \pm 0.04 *$ \\
\hline $\begin{array}{l}\text { Nasal length } \\
\text { (In centimeters) }\end{array}$ & $4.81 \pm 0.04$ & $5.18 \pm 0.04 *$ & $4.47 \pm 0.04$ & $3.77 \pm 0.05 *$ \\
\hline Nasal index & $86.58 \pm 1.20$ & $77.76 \pm 0.82 *$ & $81.75 \pm 1.14$ & $102.27 \pm 1.31 *$ \\
\hline
\end{tabular}

From table 3, the Ibibio males have significantly $(\mathrm{p}<0.05)$ wider nose than the Yakurr males while the Yakurr males have significantly longer nose than the Ibibio males. The nasal index of the Ibibio males is platyrrhine and is significantly $(\mathrm{p}<0.05)$ higher than that of the Yakurr males which is mesorrhine. The Yakurr females have significantly $(p<0.05)$ wider nose and higher nasal index than the Ibibio females while the Ibibio females have significantly $(\mathrm{p}<0.05)$ longer nose than the Yakurr females. Table 3 also showed that the nasal length for all the groups studied was significantly higher $(\mathrm{p}<0.05)$ than the nasal width except the Yakurr females who had a higher value for the nasal width than the nasal length and this difference is not significant $(\mathrm{p}<0.05)$. The nasal index of the Yakurr females is platyrrhine and is significantly higher $(\mathrm{p}<0.05)$ than that of the Ibibio females which is mesorrhine.

\section{Discussion}

There is wide variation in the size and shape of the nose and ethnic influences can result in different appearances of the nose [2]. The nose has been considered as one of the best clues to racial origin [21]. Irrespective of the nose type, several studies have documented higher values of nasal parameters for the males [7],[22],[14],[15],[23]. In this study, all the nasal parameters (length, width, and nasal index) were significantly higher in the males except in the Yakurr ethnic group where the nasal index is significantly higher in the females. A few studies have also documented a higher nasal index in the females [16],[24]. Most studies have recorded longer nasal length [7],[25],[26] than the nasal width but in this present study, the Yakurr females were found to have a significantly wider dimension than the length.

From previous studies, sexual dimorphism has been a prominent feature in the values of nasal parameters [14],[15],[23],[26]. In this study, all the nasal parameters studied were found to be statistically different between the sexes. However, few studies have reported the non-existence of gender difference [18], [24].

The nasal index is said to be related to regional and climatic differences[11] and one of the best clues to racial origin[21]. It would be expected that ethnic groups in the same climatic region should not have much difference in their nasal indices. In this present study, using two ethic groups from South South zone of Nigeria, statistically significant differences in the nasal parameters were found to exist. Some other Nigerian studies have also recorded similar results [14],[15]. From these studies, it appears that the uniqueness of the nose exists in geographical clusters and may be determined by the environment and genetic constitution.

\section{Conclusion}

The study of the nasal parameters was carried out in two ethnic groups in South South zone of Nigeria. Results obtained from the study strongly suggest that the nose could be a useful anthropometrical tool in separating gender and ethnic groups. These differences appear to exist in geographical clusters irrespective of the climate.

\section{References}

[1] N. Powell and B. Homphresy. Proportion of aesthetic face. Theme-Stratton, New York, 1984.

[2] Z. Heidari, H. Mahmoudzadeh-Saghed, T. Khammar and M. Khammar. Anthropometric measurement of the external nose in 25year old Sistani and Baluch aborigine women in the South-West Iran. Folio morphology, 68 (2), 2009, 88-92.

[3] B. Indira and J. C. Sharma. The Nose in relation to Head and face - An anthropometric study. Indian J. of Otolaryngology and Head and Neck surgery, 11(4), 1959.

[4] R. L. Hall and D. A. Hall. Geographic variation of native people along the pacific coast. Hum. Biol., 67(3), 1995, 407-426.

[5] B. Daniel. Racial anthropology and genetics of the Lebanese. Available in www.nasalindexoflebanese.com.2002,1-2.

[6] L. Kashmira. Different types of Noses, 2011. Available in: http://www.buzzle.com/articles/diferent-types-of-noses.html.

[7] G. Staka, F. Dragidella and M. Disha. Anthropometric studies of nasal index of the Kosovo Albanian population. Antrocom Online Journal of Anthropology, 8(2), 2012, 457-462.

[8] B. Xu, Y Wang, J. Ma, M. Li, and L. Xu A computer-aid study on the craniofacial features of Archang race in Yunnan Province of China. Hua Xi Qiang Yi Xue Za Zhi, 19 (6), 2011, 394-396. 
[9] P. Williams, M. Dyson, J. E. Dussak, L. H. Bannister, M. M. Berry, P. Collins, and M. W. J Ferguson. Skeletal system. Gray's Anathomy, $38^{\text {th }}$ Ed., Churchill Livingstone, Edinburgh, 1995, 609-612.

[10] J. S. Weiner. Nose shape and climate. American Journals of Phys. Anthrop ., 12, 1954, 615-618.

[11] L. G. Farkas, I. R. kolar, I. R. Munro. Abstract of geography of the nose, a morphometric study. Aesth. Plast. Surg., 10 (4), 1986, 191-223.

[12] H. H. Risley. The people of India. $2^{\text {nd }}$ Ed. Oriental Books, Delhi, 1915, 395-399.

[13] A. Thomson and L. H. D. Buxton. Man's nasal index in relation to certain climatic conditions. J. R. Anthropol. Inst., 59, 1923, 92122.

[14] C. Eliakim-Ikechukwu, T. Bassey, and C. Ihentuge. Study of the Nasal Indices and Bialar Angle of the Ibo and Yoruba Ethnic groups of Nigeria. J. of Biol. Agric. and Healthcare, 2(11), 2012, 149-152.

[15] G. S. Olabiyi, A. A. Oremosu, and C. C. Noranha. Nasal indices among major ethnic group in southern Nigeria. Sci. Res. Essay, 2(1), 2007, 20-22.

[16] G.S. Oladipo, P. D. Okoh, P. A. Akande, and M.O. Oyakhire. Anthropometric study of some craniofacial parameters: Head circumference, Nasal height, Nasal width and Nasal index of adult Omoku indigenes of Nigeria. Am. J. Sci. Ind. Res .2(1), 2011, 5457.

[17] G. S. Oladipo, M. O. Eroje, and H. B. Fahwehinmi. Athropometric comparison of the nasal indices between the Andoni and Okrika ethnic group of Rivers State, Nigeria. Int. J. Med. Sc.i,1(4), 2009, 135-137.

[18] D. E. O. Eboh and E. A. John (2011). Morphological amendment of face and nose shape among the Ukwuanis in Delta state, Nigeria. J. Exp.Clin.Anat., 10(1), 2011, 4-8.

[19] H. B. Fahwehninmi and A. E. Ligha. Subnasale to Gnathion distance and nasal index of children with homozygous sickle cell disease in Port-Harcourt. Eur. J. Gen. Med., 7(2), 2010, 197-202.

[20] T. Romo and M. T. Abraham. The Ethnic Nose. Facial Plast. Surg., 19(3), 2003, 269-278.

[21] G. Madison. The passing of the Great race. Part 1: Language and Nationality. Chap. 2, 2004, 1-6.

[22] R. G. Franciscus and J. C. Long. variation in human nasal height and breath. Am. J. Phys. Anthropol., 85 (40), 1991, $419-427$.

[23] A. K. Pandey. Cephalofacial variation among Onges. Kamla-Raj Anthropologist, 8(4), 2006, 245-249.

[24] D. E. O. Eboh. Nasal indices among Bini Adolescents. Int. J. Morphol., 29(4),2011, 1231-1234.

[25] D. R. Omotosho, O. O. Oludiran, and C. L. Salepa. Nasofacial anthropometry of adult Bini tribe in Nigeria. Afr. J. Biomed. Res., 14, 2011, 219-221.

[26] E. A. Osunwoke, F. S. Amah-Tariah, I. O. Obia, I. M. Ekere, and O. Ede. Asian J. of Med.Scs., 3(2),2011, 71-73. 